\title{
SEALING SITES ON MACQUARIE ISLAND: AN ARCHAEOLOGICAL SURVEY
}

\author{
by $\mathrm{K}$. Townrow
}

(with five text-figures and three plates)

TOWNROW, K., 1988 (viii): Sealing sites on Macquarie Island: an archaeological survey. Pap. Proc. Roy. Soc. Tasm. 122(1): I5 25, 3 pl. Paper presented at the Macquarie Island Symposium, Hobart, May 1987. https://doi.org/10.26749/rstpp.122.1.153 ISSN 0080 4703. Department of Lands, Parks and Wildlife, Hobart, Tasmania, Australia.

A brief history of Macquarie Island is outlined with particular note of the different types of sites and sealing equipment used. Their spatial relationships and the evidence for technological change are viewed in the light of this historical evidence. The results of a small excavation challenge the historically derived view that living quarters were continuously repaired and/or re-used. Problems in the management of these resources are outlined.

Key Words: Macquarie Island, sealing, early Australasian industry, early technology, archaeology.

\section{INTRODUCTION}

Macquarie Island is a subantarctic island situated in the Southern Ocean at latitude $54^{\circ} 30^{\prime} \mathrm{S}$ and longitude $158^{\circ} 57^{\prime} \mathrm{E}$. It lies approximately $1500 \mathrm{~km}$ southsoutheast of Tasmania and $640 \mathrm{~km}$ west of the Auckland Islands. The island is approximately $34 \mathrm{~km}$ long. Its width varies from approximately $250 \mathrm{~m}$ at the Isthmus to a maximum of $5 \mathrm{~km}$. The island is dominated by a central plateau area which is, on average, $150 \mathrm{~m}$ high. The coastal fringe offers no good all-weather anchorages. The fauna exploited by the sealers is concentrated on this coastal fringe and includes fur and elephant seals and four species of penguins. The vegetation consists of low shrubs and tussock with no trees. The climate can generally be described as wet, windy, cold-temperate, foggy and humid with a small temperature range.

The cultural remains on the island fall into three categories: shipwreck material, Australasian Antarctic Expedition sites and sealing sites. The sealing sites include living quarters and production sites. Prior to the survey described here, limited work had been conducted on the island by Davies (1982). The current survey was conducted during the five-week Australian National Antarctic Research Expedition (ANARE) summer season in 1986-87. Its main objectives were to survey all the cultural remains on the island, assess their condition and the archaeological potential of the island, and make management recommendations. The survey was funded by a grant from the National Estate, through the Australian Heritage Commission. It was administered by the Department of Land, Parks and Wildlife.
MACQUARIE ISLAND

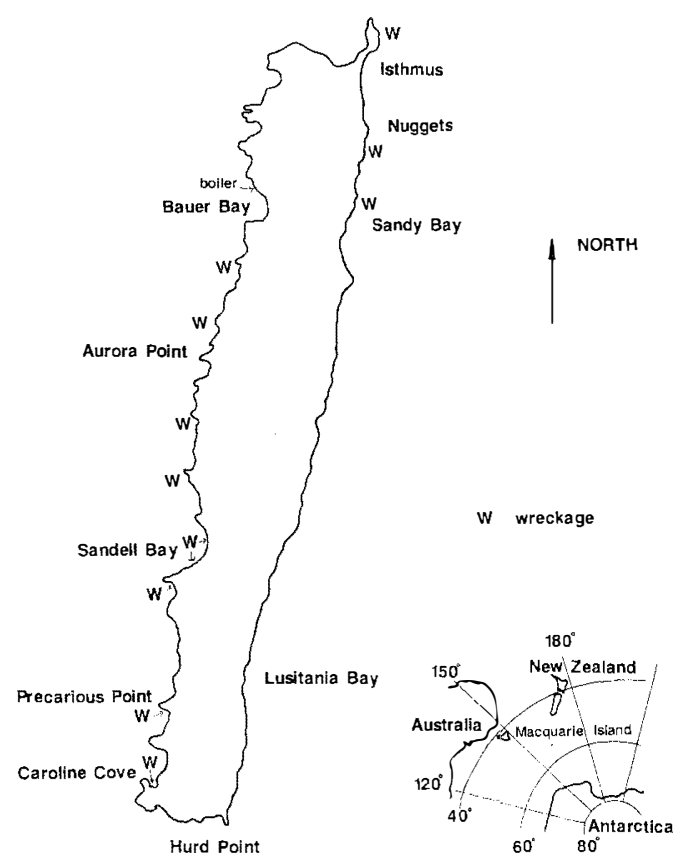

FIG.l - Macquarie Island, showing sources of cultural remains. 
The history of Macquarie Island is an example of the industries of the new colonies, and their technology. Emphasis from the outset was on exploitation, with maximum gain for minimum input, rather than management for maintenance of the resource. This was especially so in the earliest stages. The fur seal population was rapidly devastated and the activity became non-viable; but there was a "fall back". Elephant seal oil production quickly took over and lasted much longer. Penguins were exploited for a short period of time later. Initially the production of oil was by tryworks. This type of technology was crude and inefficient but productive. The more efficient digester technology was only introduced about 80 years later, under the management of one man, Joseph Hatch, who may have been thinking about a more longterm industry, rather than the "hit and run"style of his predecessors.

\section{HISTORICAL BACKGROUND}

Macquarie Island was discovered in 1810 by Captain Hasselborough of the Perseverance while seeking fur seals (this, and other references in this section, from Cumpston (1968)). A gang was landed in July 1810 to assess the potential of the fur seal population and start harvesting. They considered the potential to be good and tried to keep secret the location of the island, but they failed and by December 1810 a further three gangs had been landed. One of these started rendering down elephant seals, in addition to hunting fur seals. At this stage, gangs appear to have comprised about twelve men. The earliest record of a hut was of one built from the sails and skins salvaged off the wreck of the Camphell Macquarie in 1812, but it was soon accidently burned down. The visit of the Mary and Sally in 1813, however, indicates that there were huts at the Isthmus, as a gang of eleven men was landed. Tryworks had certainly been established, as men were sent ashore to put them in order (Cumpston 1968, p.30). This party also established living quarters and a tryworks at Sandy Bay.

It appears that the island was then worked seasonally by two to three gangs until the late $1820^{\circ}$ s. Underwood and MacQueen were the main operators. Huts and tryworks were located at the Isthmus, Sandy Bay, Lusitania Bay and Caroline Cove. It is not clear when the Hurd Point tryworks were first established, but graves dating from 1821 26 , described by Cook in 1851, would suggest a starting point. Bellingshausen (a Russian explorer) mentioned separate gangs, totalling 40 men, working the island during his visit in 1820 . By that time, the only industry appears to have been elephant seal oil production.

Fur seals were slaughtered to the point of virtual extinction within five years. Records of the number of pelts taken are contradictory, but it certainly exceeded 150000 . Both historically and archaeologically, very little evidence has been found to substantiate the location or locations of this ind ustry on the island.

Underwood ceased operations in 1828 and McQueen in 1829. Bellingshausen's description of the headman's hut at Sandy Bay (Cumpston 1968 , p.45) provides an idea of the type of dwellings being used on the island at this time. It was

" 20 feet long by 10 feet broad, inside it was lined with skins of seals, the outside was covered with a kind of grass which grows on the island. At one end there was a small hearth, and a lamp was always kept alight. Beside the hearth was a bedstead. Provisions were stored at the other end of the hut."

Windows are described as bladders st retched over holes in the wall. Carpenters had been employed in various gangs, and it is assumed that timber brought down on ships (and perhaps some shipwreck material) was used to form, at least, a framework for the hut. From 1830 to 1874 , there are only records for three trips to Macquarie Island. John Cook's gang of 14 men worked the North End in 1851. His diary provides an insight into the scale of operations in former times. He mentions huts and old casks at a place that appears to have been Unity Bay, and describes the South End works as consisting of houses, tryworks,.two cooper's shops and seven graves. Of North Head he states (Cumpston 1968, p.78) that

"Our flat seems to have been where the most business has been done. Over one dozen old houses and a great quantity of bones and ... hoops (are) buried here; there are Tri-pots set all about in different places; there are 2 graves on the flat ..."

Between 1860 and 1873 there are no shipping records of visits to Macquarie Island at all. There was a brief period of greater interest in elephant seal oil production between 1874 and 1884 by Nichol and Tucker, followed by Cormack, Elder and $\mathrm{Co}$. Activity appears to have been concentrated initially between the Isthmus and Sandy Bay, with repairs and additions to huts. Existing trypots were re-used with relocation of some to Nuggets Creek. Cormack, Elder and Co. gradually extended operations over the ten-year period to include 
Lusitania Bay and Hurd Point. Gangs were generally smaller than in early years, averaging eight men.

Intermittent working continued on the island until 1889 when Joseph Hatch began to dominate operations. Hatch was a New Zealand entrepeneur who became involved in the trade initially to supplement bis pharmaceutical business. He had gangs of about eight men operating on the island for the next 30 years. During this period, the transition was made from a low-technology, small capital operation to a more intensive and expensive ind ustry. Headquarters were initially at Lusitania Bay. Here, elephant seals were rendered down and the exploitation of the king penguin colony began. Digesters were introduced at Lusitania in November 1889. Coal, timber and firewood then became regular items on the list of stores taken to the island. Depots in other parts of the island were also used. For example, the Gratitude collected oil from North End, South End and Lusitania Bay in February 1891

In early 1892, Hatch's headquarters were transferred to the Nuggets. A gradual transition from the exploitation of king penguins to royal penguins also seems to have begun. This was possibly because of the problems of fermentation of the king penguin oil, since it had not been possible to reduce the blood content in it, and/or too great a reduction in king penguin numbers. Digesters and boilers were also set up at the Isthmus, Hurd Point and Hasselborough Bay. The industry then settled into a two-part operation conducted in two seasons: the royal penguin season operated from the Nuggets during November and December and the elephant seal season operated from North Head from mid-August until the end of October. Hatch's confidence in being able to maintain a continuing operation on Macquarie Island seems to be reflected in the introduction of digester plants. He also secured a sole occupational licence in 1902.

However, opposition to his operation began during the 1910's. Headed by Mawson, who had led the 1911-14 Australasian Antarctic Expedition, a campaign to declare the island a nature reserve and to condemn the royal penguin industry, in particular, gained momentum. After a brief respite in this campaign, during World War I, it seems to have become somewhat inflammatory. Claims, often by people who had never been to the island, became increasingly exaggerated. Despite continual public denials by Hatch of these exaggerated claims, he was finally forced, through the cancellation of his licence, to cease operations in 1920. Even without this cancellation, he might not have been able to continue, due to increasing financial difficulties.

\section{ARCHAEOLOGICAL EVIDENCE}

An archaeological survey of the island was undertaken in late 1986-early 1987. The sealing activities have left three main categories of remains; shipwreck material, living quarters and two types of production sites. Although all categories are interrelated, they are not necessarily all represented at every site. Living sites are distinct from production sites, in that they contain either tryworks or steam digester plants. There would appear to have been little or no intermingling of the functional use of the huts.

\section{Shipwreck Material}

Without diving it was only possible to observe the material which has gathered along the coastlines in the form of flotsam and jetsam. This is mixed with some of the refuse of the Southern Ocean. The material is concentrated on the east coast between North Head and Sandy Bay and right along the west coast. The east coast scatter is undoubtedly related to the concentration of known shipwrecks in this area. The scatter on the west coast is probably attributable to its wind ward location, in the path of the general drift of the Southern Ocean. The last obvious remains of the Gratitude, which was beached at the Nuggets, were carried out to sea in 197576 (G. Copson, pers. comm.).

\section{Living Quarters}

Quarters can be found at the Isthmus, the Nuggets, Lusitania Bay and Hurd Point. There are possibly remains of living quarters at Sandy Bay but they have deteriorated to the point of being nebulous.

Three huts were identified at the Isthmus. All are located under the eastern lee of Razorback Hill. Associated with these huts was a large scatter of artefacts, including parts of an iron stove, a clay tobacco pipe bowl, barrel staves and assorted timber.

The Nuggets living quarters consist of a large and small hut. The larger is more clearly defined by a row of large beach stones on its seaward side. The layout of floorboards at this hut suggests that the smaller, sleeping area was at the northeast end of the hut with a larger, communal/store area at the other. Adjacent to the western corner of the hut is a 
18

K. Townrow

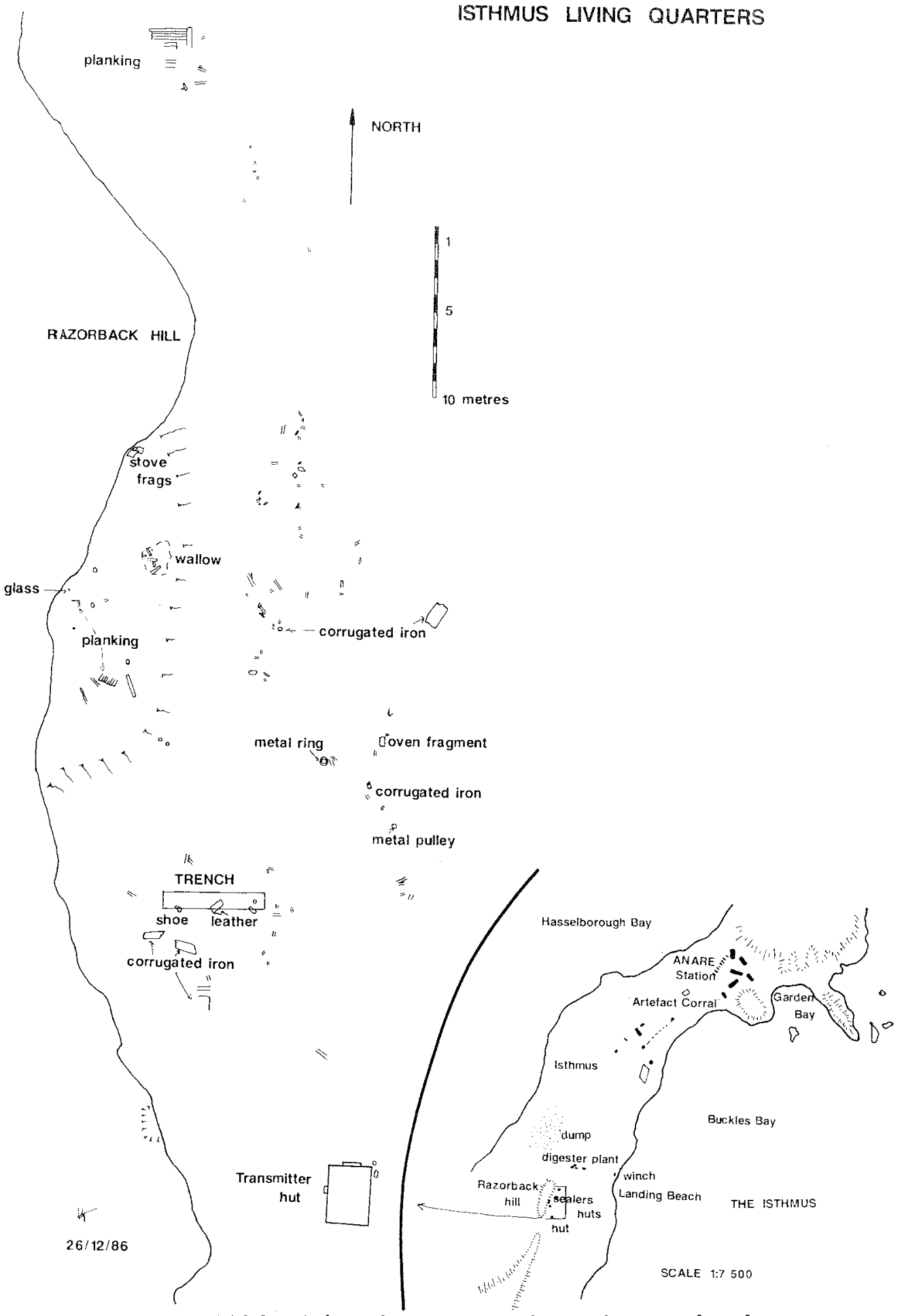

FIG.2 - Isthmus living quarters, showing location of artefacts. 


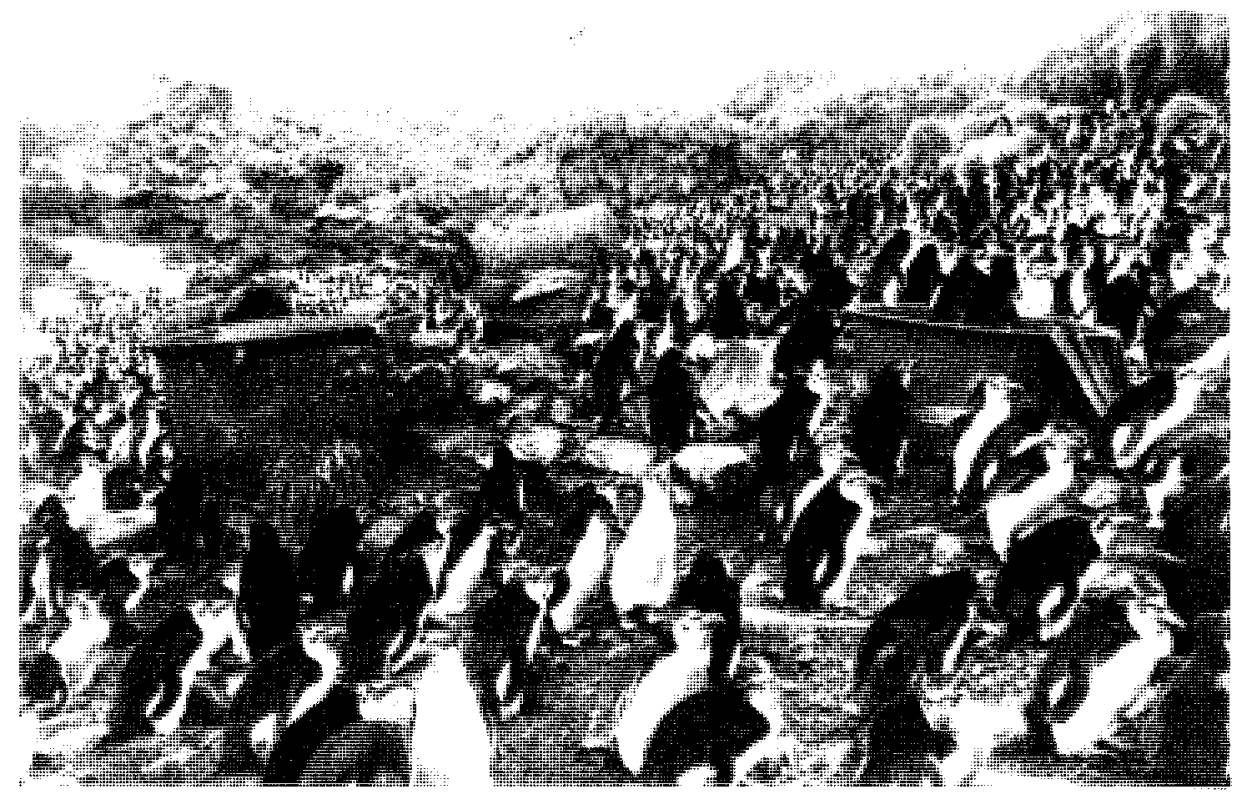

PLATE 1

Hurd Point tryworks, an example of the problems of archaeological survey during the penguin breeding season.

small outhouse, which may have acted as an extra store or pantry area. The small living quarters are defined by some corner posts. Associated with the huts are parts of a stove, a standing mooring post, bricks, a mallet head and bottle glass fragments.

Both the Hurd Point and Lusitania Bay living quarters were almost totally obscured when fieldwork was being conducted, because both sites are situated within large royal or king penguin colonies (plate 1). However, one living hut was positively identified at each site. The Hurd Point hut lies on the western edge of the colony, perched half-way up the beach bank. As with the Isthmus huts, it had stilts on the seaward side. The Lusitania hut was much smaller than the others and, at this stage, could only be identified by four corner posts, an anvil, barrel base and timber scatter.

\section{Production Sites}

These can be divided into two types: trypot works and digester works. Evidence of tryworks is present at Hurd Point, Caroline Cove, Lusitania Bay and the Isthmus. Of these sites, Hurd Point is the most intact example, with a cluster of six trypots and the scattered remains of three others in the general vicinity. The cluster of trypots is arranged so that one feeds into two. Two such groups are positioned north-south down the beach bank. Remains of a building which housed these works are present. At the other sites, tryworks are represented by two trypots at Caroline Cove, one of which is three-quarters buried; one at Lusitania Bay with associated timber; and one at the Isthmus, almost totally buried.

Digester works can be found at the Isthmus, the Nuggets, Hasselborough Bay, Lusitania Bay and Hurd Point. Both Hurd Point and Hasselborough Bay have only one small digester and one boiler. Remains of the sheds which housed them are evident at both locations. Lusitania Bay has one small and one large digester (plate 2) and a boiler, which were all originally housed in a large shed. The Nuggets has a group of two small and two large digesters fed by three boilers within a shed. Two discarded boilers lie to the southwest of the site. The Isthmus works consist of two digesters, one boiler, and a discarded boiler to the east of the site. Both these sites also have the foundations of the sheds which housed them. Artefacts associated with this type of site include tools, such as vices and anvils, barrels, coal and settling tanks. The Nuggets and Lusitania Bay sites both appear to have piped in water to the boilers. At the Nuggets, there are two stationary pumps which would have been used for this purpose. 


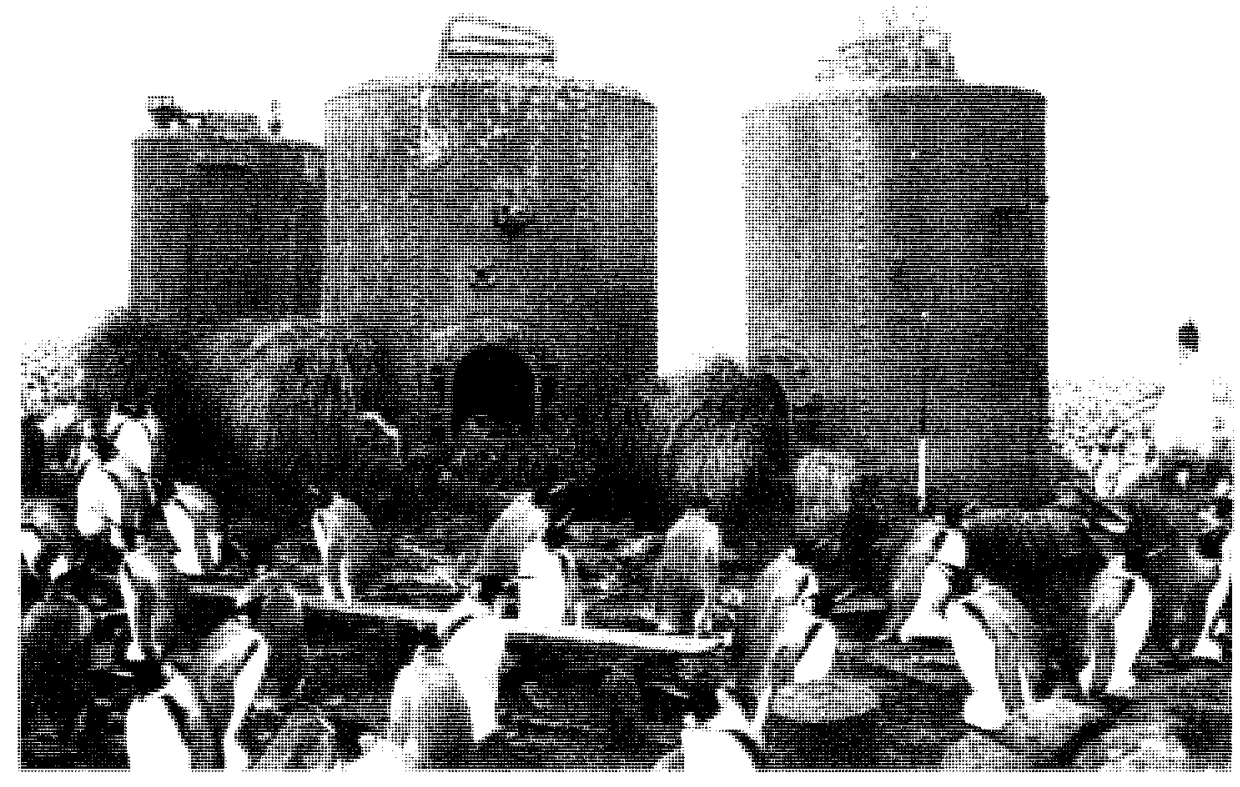

PLATE 2

Lusitania Bay, steam digester plant.

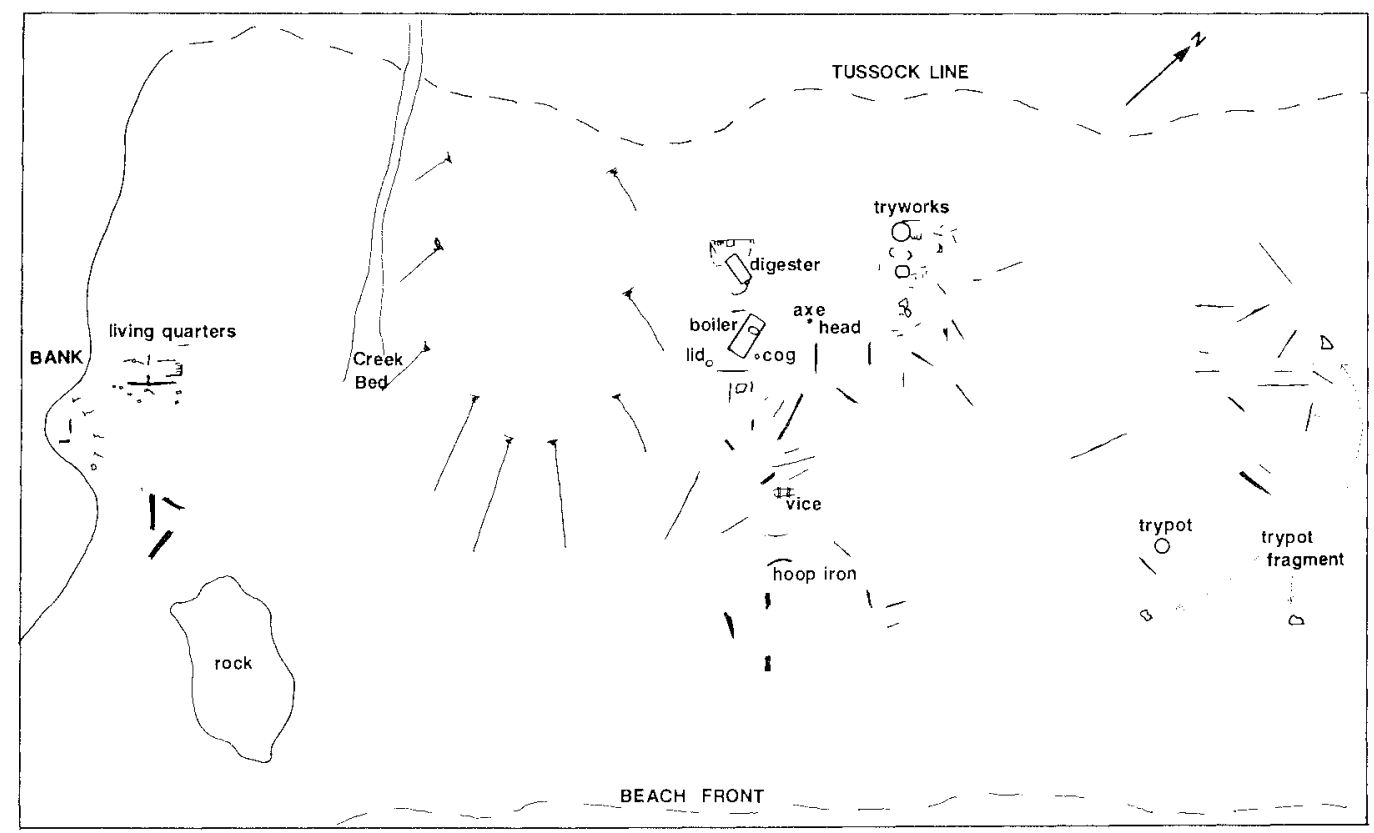

FIG.3 - Hurd Point production site, showing location of artefacts. 


\section{EXCAVATION}

A $1 \mathrm{~m}$ by $6 \mathrm{~m}$ trial trench was excavated through one of the huts at the Isthmus (plate 3 ). The excavation was conducted in an attempt to determine the effectiveness of this form of investigation on the island. The specific site was chosen because the hut was known to have been used by Hatch's men in the 1910's (archival photographs) thereby providing an end-date to occupation at this site. Hence it could be more reliably assessed whether the hut represented the re-use of an earlier construction. The trench was orientated to run east-west, covering what was thought to be the side of the structure. Standard archaeological procedure was followed, although the soil was not sieved for artefacts.

The trench established that considerable quantities of material are being obscured by vegetation. The main location of this material was just beneath the regrowth which has been the principal agent in its preservation. Unfortunately the trench did not expose the side of the hut but appears to have uncovered a "cold porch" or workshop area where tools and the horse harness could have been stored. The horse was undoubtedly one of the Clydesdales used by Hatch's men to pull the blubber sled, during the later phase of his operations. Only the floor joists and posts with some wall planking, complete with tar (bitumen insulation) paper, remained of the hut. It, therefore, seems likely that the floorboards were scavenged at a later date and perhaps used to repair other buildings or as fuel. The hut appears to have been stilted to the east (this is confirmed by archival photographs). It was not possible to determine whether the hut had been refurbished (the trench proved to be too small), although it may not have represented an original 1820 's hut, since a penguin bone refuse pile was found under the floor joists which may pre-date the hut. The total depth of occupation at the western end was $1.1 \mathrm{~m}$. It was generally found that the state of preservation of the artefacts was good. Leather, iron, fabric and wood artefacts were in reasonable condition, although, due to the acidity of the soil, bone artefacts were not as well preserved. The finds included a carthorse harness, various iron tools, guttering, wal insulation, glassware, domestic pottery, elephant seal teeth, two spent cartridges from different calibre firearms and parts of a cupboard or tea-chest.

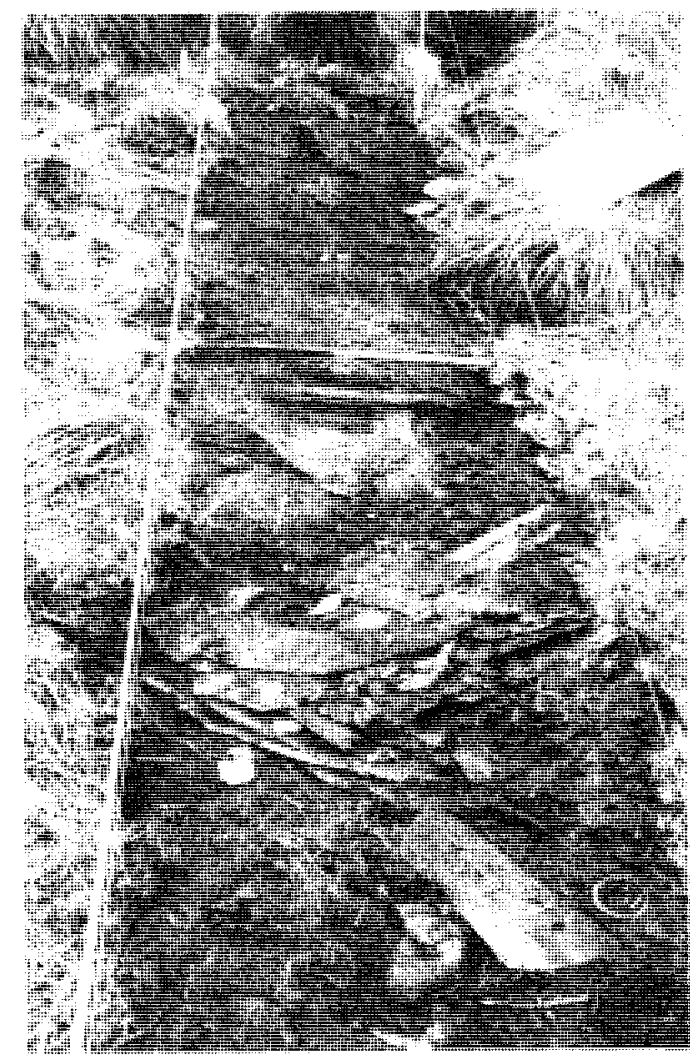

PLATE 3 - Trial trench. Isthmus living quarters, after removal of vegetation.

\section{DISCUSSION}

From this evidence the following comments can be made:

(1) Where living quarters and production sites are found at the one location, the living quarters are situated $25-50 \mathrm{~m}$ upwind of the production sites, unless confined by topographical restraints (for example see fig. 3). The reason for this seems to be purely one of relative comfort. The smell of rancid blubber from the boiling process was notorious.

(2) Living quarters appear to have a rather limited life. No evidence was found of the early tussock-with-wood frame huts. Remains of huts were identified at the Isthmus, some of them possibly from the dozen huts described in 1851, but none could be positively established as such. The historical records mention constant repairs to huts, but the limited excavation undertaken suggests that the same huts were not continuously repaired. 

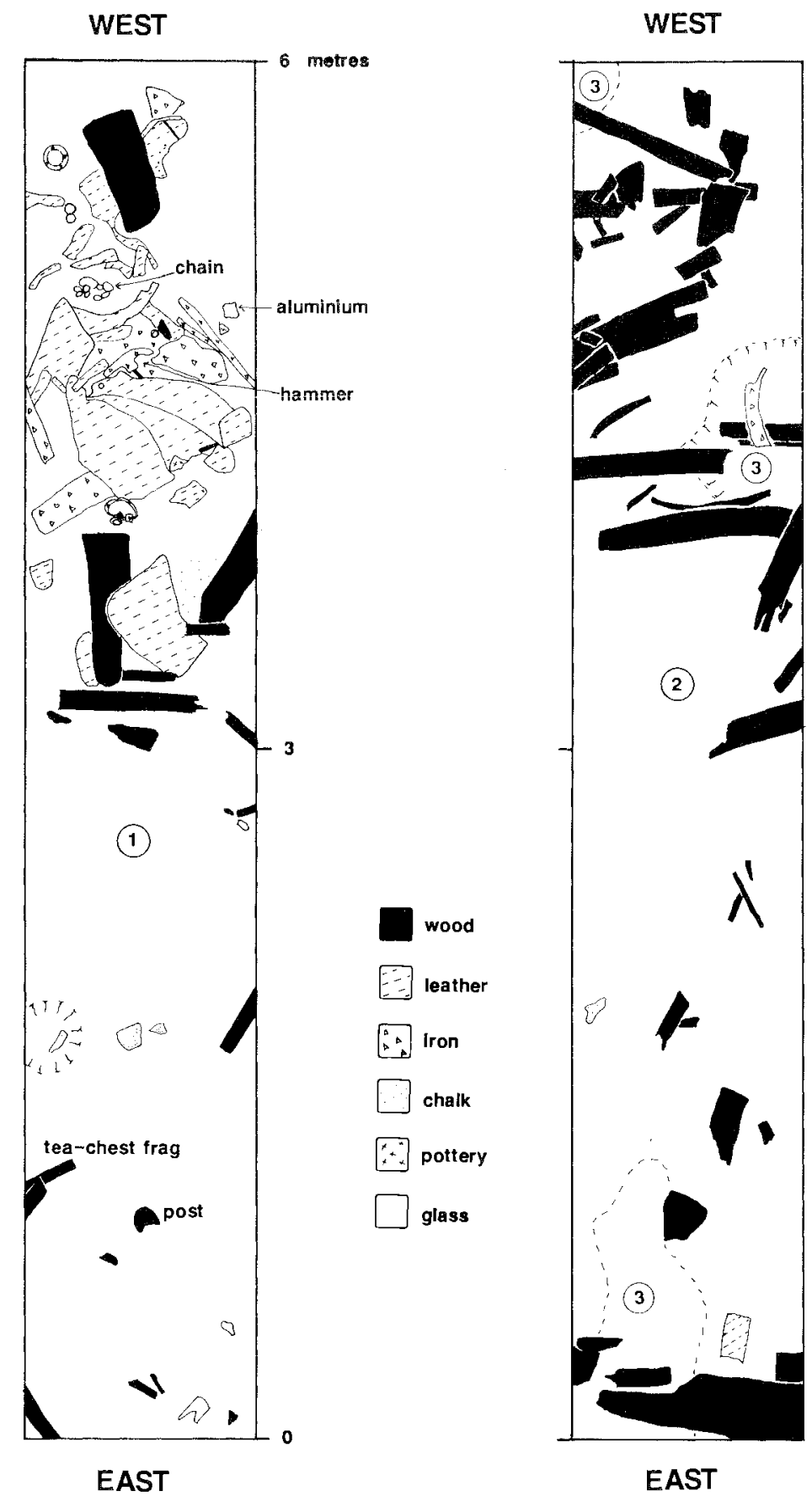

FIG.4 - Isthmus test trench - horizontal layout; numbers refer to different levels of excavation. 

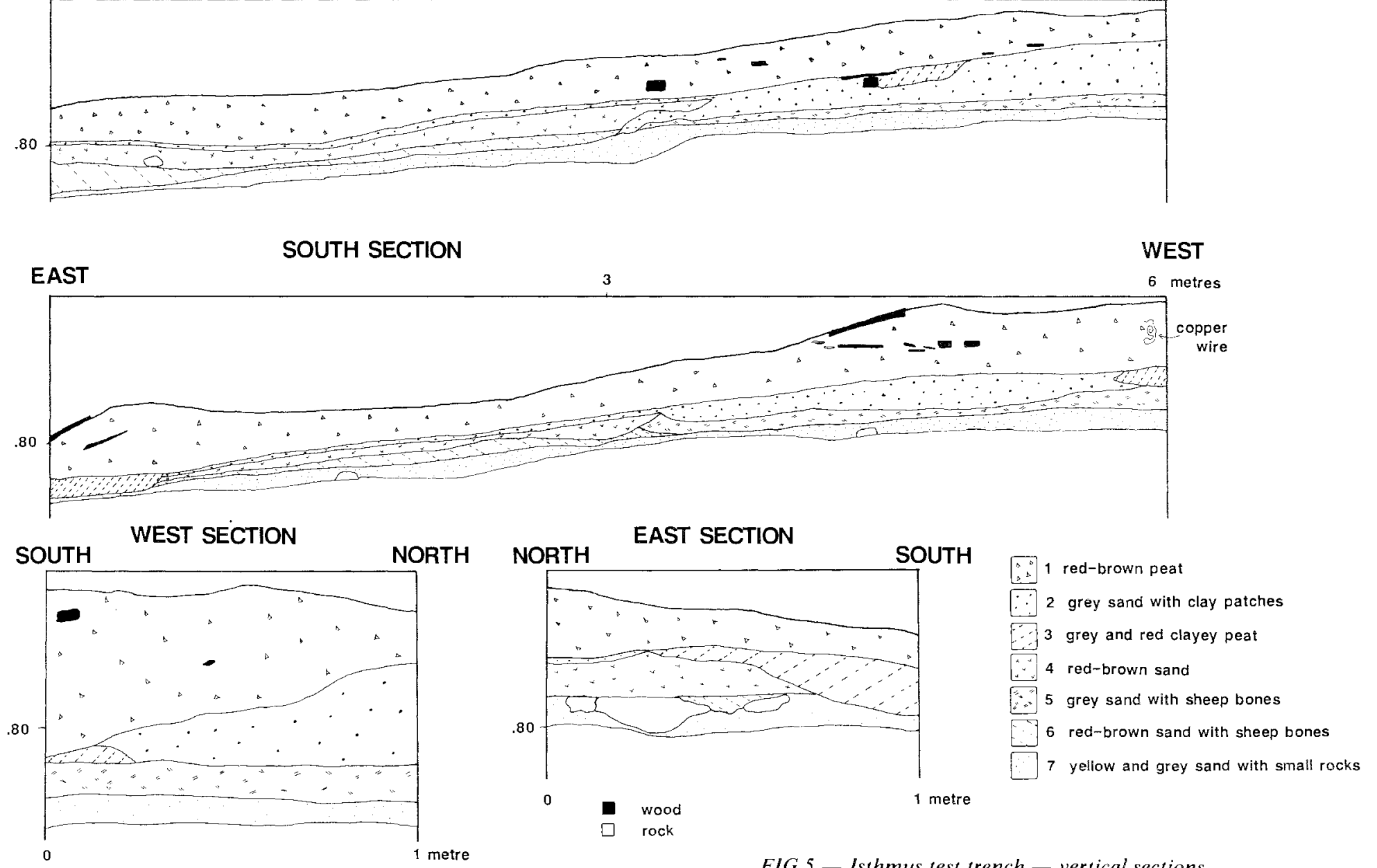
Instead, when a hut was beyond repair, material was salvaged and re-used in building a new hut in a new location. However, additional excavations would need to be carried out to confirm this or highlight differences between sites.

(3) The tryworks reflect the longer industrial phase and have consequentiy suffered the most from re-use and/or relocation of the pots from their original situations. The loss of context of any artefact is directly related to its portability. The trypots, being relatively portible, compared to boilers and digesters, have been more subject to this problem.

(4) The trypots show no uniformity of size or design. They have litile, if any, decoration. This reflects the low level of tech nology required for the boiling-down process.

(5) This simple technology was in use during the peak period of production between 1810 and 1830 (Hindell \& Burton, this volume). The obvious reason contributing to the relative success of this technology, compared to the "higher technology" of steam digesters, was greater availability of the resource, but other factors may have contributed, such as higher labour input per gang and, in total stimulus of rivalry between gangs or the stimulus of higher profitability

(6) The use of digesters in the production of seal and penguin oils would appear to be unique to Macquarie Island. It is likely that they were adapted from similar plants used on whaling boats to render down blubber. In the whaling industry, similar types of digesters, of Norwegian design, were in use by 1889 (Tonenessen \& Johnsen 1982). At the time of their introduction on Macquarie Island, at Lusitania Bay in 1889, therefore, they may have been "state of the art".

(7) The digesters appear to represent two phases of development; the smaller and single sets representing the trial usage and the larger representing the more cost efficient locations for this type of machinery. Size may also be related to the resource being used. The larger digesters are present at the Nuggets and Lusitania Bay, indicating that a larger size of digester was viable where large numbers of easily obtainable penguins were available, but was not necessary or viable when rendering down elephant seal blubber.

(8) The digesters and boilers represent an increasing availability of large manufactured machinery during the late nineteenth and early twentieth centuries. They are standardised in design and manufacture, made from hot-rivetted sheet iron. There are distinct sizes. The digester works, therefore, may be said to reflect the rapid changes in industrial technology in the Australasian colonies during this time.

(9) The sites represent entrepreneurial activity rather than a Government-initiated or subsidised industry. As such, the remains tend to reflect their functional and essentially temporary nature rather than any degree of permanence. Equipment was left where it stood because it was not a profitable proposition to remove it.

(10) The sites may also be a reflection on general work and living conditions in Australia and New Zealand during the last century. Conditions on Macquarie Island were always harsh, yet men were prepared to work there, of ten for relatively long periods. This would suggest that either there was not a sufficient range of job opportunities at home or that conditions were not substantially different or both.

\section{FACTORS AFFECTING THE SURVIVAL OF REMAINS}

Factors affecting the rate of attrition of this resource are weather and sea, flora and fauna, and human intervention.

The climate of Macquarie Island is cold, wet and saline. This has resulted in the deterioration of ironwork, the collapse and scattering of huts and the rotting of wood. Storms add to this, with high seas tending to redistribute remains along the coast.

The fauna can be a problem. The survival of remains within penguin rookeries is limited. Seals wallow, and tend to relocate or obscure remains or expose them to the weather. Although the flora, particularly tussock-grass, tends to totally obscure remains, excavation has shown that it may also act as a protective covering, thereby keeping the remains in a damp but relatively stable environment.

Human intervention has possibly been the greatest drain on the resource. Initially, any available salvageable material seems to have been re-used where at all possible. Although this is also part of the archaeological record, it tends to introduce interpretative problems. In later years, the evidence that has retained its context appears to have suffered from souveniring, and from the lack of a policy on what was to be done with the artefacts and the sites. The policy of leaving artefacts in situ, unless under immediate threat, was introduced in 1982 and has helped to reduce the amount of preventable damage caused by human intervention. 


\section{CONCLUSION}

The survey conducted on Macquarie Island during the 1986-87 summer season indicates its potential for increasing understanding of early Australasian ind ustry and technology. The industry and its remains may also reflect some societal attitudes of that time, in regard to the use of primary resources. It is important that the work done in the study is followed up, through additional excavation and by survey, during the non-breeding season, of remains within penguin colonies Archaeological evidence, by providing additional information and throwing new light on present records, represents the best remaining source of material for understanding the early human activity on Macquarie Island.

\section{REFERENCES}

CUMPSTON, J.S., 1968: Macquarie Island. $A N A R E$ Sci. Rep., Ser. A(1). Antarctic Division. Department of External Affairs. Australia.

DAVIES, M., 1982: Macquarie Island: Archaeological Report. National Parks and Wildlife Service Report, unpubl.

HINDELL, M.\& BURTON H., 1988: The history of the elephant seal industry at Macquarie Island and an estimate of the pre-sealing numbers. Pap Proc. R. Soc. Tasm. 122(1): $159-176$.

TONNESSON, J.N. \& JOHNSEN, A.L., 1982: THE HISTORY OF MODERN WHALING. Australian National University Press, Canberra.

(accepted 18 September 1987) 